\title{
LA CUEVA DEL SOL, UN MARCADOR SOLAR EN LA SIERRA DE LA PLATA (TARIFA, CÁDIZ)
}

\author{
CUEVA DEL SOL, A SOLAR MARKER IN THE SIERRA DE LA PLATA (TARIFA, CÁDIZ)
}

\author{
MERCEDES VERSACI INSÚA* / IGNACIO GONZÁLEZ MARTÍNEZ-PAIS** / \\ MARÍA LAZARICH*** / FRANCISCO TORRES ABRIL**** / ANA CARRERAS EGAÑA***** / \\ MIGUEL GALINDO DEL POZO****** / SIMÓN PARDO DE DONLEBÚN $* * * * * * *$
}

Resumen: En el ámbito geográfico que nos ocupa, entornos de la Laguna de la Janda y Campo de Gibraltar, existen unos trescientos abrigos con arte rupestre escasamente estudiados. En veintidós de ellos está representada la figura soliforme en sus paredes rocosas. La denominada Cueva del Sol es uno de los abrigos que forman parte de este conjunto. Sus especiales características, tanto geográficas como iconográficas, y los reveladores resultados de observaciones astronómicas apuntan a la existencia de un marcador solar del solsticio de invierno, y convierten a esta cavidad en una de las más excepcionales del conjunto $\mathrm{y}$, tal vez, de la península ibérica. Los datos obtenidos hacen que este abrigo pueda llevarnos a determinar algunos aspectos concretos sobre los cultos asociados al comportamiento solar y su función como regulador de las actividades productivas $\mathrm{y}$, por ende, acercarnos a la cosmovisión de los hacedores de estas pinturas. Para ello es condición sine qua non un análisis individual y profundo, realizado a partir de un enfoque teórico-metodológico basado sobre todo en la Arqueoastronomía, la Arqueología del Paisaje, la Semiótica o la Etnografía, entre otras disciplinas.

* Área de Prehistoria. Grupo de Investigación PAIDI HUM 812. Facultad de Filosofía y Letras. Universidad de Cádiz. C/ Dr. Gómez Ulla 1, 11003 Cádiz, España. Correo-e: mechiversaci@gmail.com.

** Instituto de Astrofísica de Canarias (IAC). C/ Vía Láctea s/n, 38205 La Laguna, S/C de Tenerife, España. Departamento de Astrofísica de la Universidad de La Laguna. C/ Molinos de Agua s/n, 38207 S/C de Tenerife. Correo-e: igm@iac.es.

*** Profesora Titular. Área de Prehistoria. Grupo de Investigación PAIDI HUM 812. Facultad de Filosofía y Letras. Universidad de Cádiz. C/ Dr. Gómez Ulla 1, 11003 Cádiz, España. Correo-e: maria.lazarich@uca.es.

\begin{abstract}
In the geographical area under study, surroundings of the Laguna de la Janda and the Campo de Gibraltar, there are over three hundred rock-shelters with cave paintings, which have barely been studied. The sun-shaped figure is depicted on the rocky walls of twenty-two of these rockshelters. The Cueva del Sol is one of the rock-shelters that forms part of this set. Due to both its special geographical and iconographic characteristics as well as the revealing results of astronomic observation that confirmed the existence of a winter solstice marker (sun dagger), this rock-shelter is one of the most exceptional of the set and maybe of the iberian peninsula. The characteristics of this rock-shelter enable us to determine some specific aspects on worship associated to the behaviour of the sun and its role in regulating production activities thus bringing us closer to the worldview of the creators of these paintings. For this purpose, a detailed and individual analysis from a theoretical and methodological approach, mainly based on Archaeoastronomy, Landscape Archaeology, Semiotics and Ethnography, amongst other disciplines, is a conditio sine qua non.
\end{abstract}

**** Área de Prehistoria. Grupo de Investigación PAIDI HUM 831. Facultad de Filosofía y Letras. Universidad de Cádiz. C/ Dr. Gómez Ulla 1, 11003 Cádiz, España. Correo-e: eldelpantano@ gmail.com.

***** Licenciada en Historia por la Universidad de Granada. Investigadora independiente. Correo-e: anacarrerasster@gmail.com.

****** Licenciado en Historia por la Universidad de Cádiz. Investigador independiente. Correo-e: galindodelpozo@hotmail.com.

******* Licenciado en Historia por la Universidad de Granada. Investigador independiente. Correo-e: sp.versaci@gmail.com. 
Palabras clave: Soliforme. Calcolítico. Arqueoastronomía. Solsticio. Marcador Solar.

\section{INTRODUCCIÓN}

El presente trabajo se enmarca dentro de un proyecto de investigación multidisciplinar mucho más amplio, centrado en el estudio de las representaciones solares y su interpretación en los abrigos con arte rupestre esquemático del extremo sur de la península ibérica.

Las primeras referencias sobre la Cueva del Sol se deben a Lothar Bergmann (1994) quien intuyó, de alguna manera, la relación de este abrigo con fenómenos astronómicos al interpretar las figuras denominadas tatuajes faciales como posibles cometas.

En 2011 visitamos por primera vez la Cueva del Sol, el cual, desde el primer momento, despertó en nosotros un interés particular por su iconografía y la peculiar organización espacial de la misma.

Como bien señalan los investigadores C. Esteban y E. Aura, en un artículo sobre la Cova del Parpalló (2001), el uso de calendarios, o mejor dicho, la capacidad de poder registrar el paso del tiempo de manera
Keywords: Sun-shaped. Chalcolithic. Archaeoastronomy. Solstice. Solar Marker.

sistemática, según nos indican los hallazgos arqueológicos, viene realizándose desde el Paleolítico. Creemos que esta fue la función que cumplían las manifestaciones gráficas plasmadas en el abrigo Cueva del Sol.

\section{EL ABRIGO: ASPECTOS GEOGRÁFICOS, GEOLÓGICOS Y GEOMORFOLÓGICOS}

La Cueva del Sol se localiza a 291 m s.n.m. en la vertiente noroeste de la Sierra de la Plata, en el término municipal de Tarifa (Cádiz) (fig. 1). Una alineación montañosa de dirección noreste-suroeste, que alcanza los 459 m s.n.m. y que termina en el océano Atlántico. Al igual que todas las sierras del Campo de Gibraltar, está constituida por potentes paquetes de areniscas de facies numídicas pertenecientes al manto del Aljibe del complejo del Campo de Gibraltar (Algarra 2008) (fig. 2). Estas areniscas y sus derrubios dan lugar a una vegetación arbórea formada fundamentalmente por alcornoques.

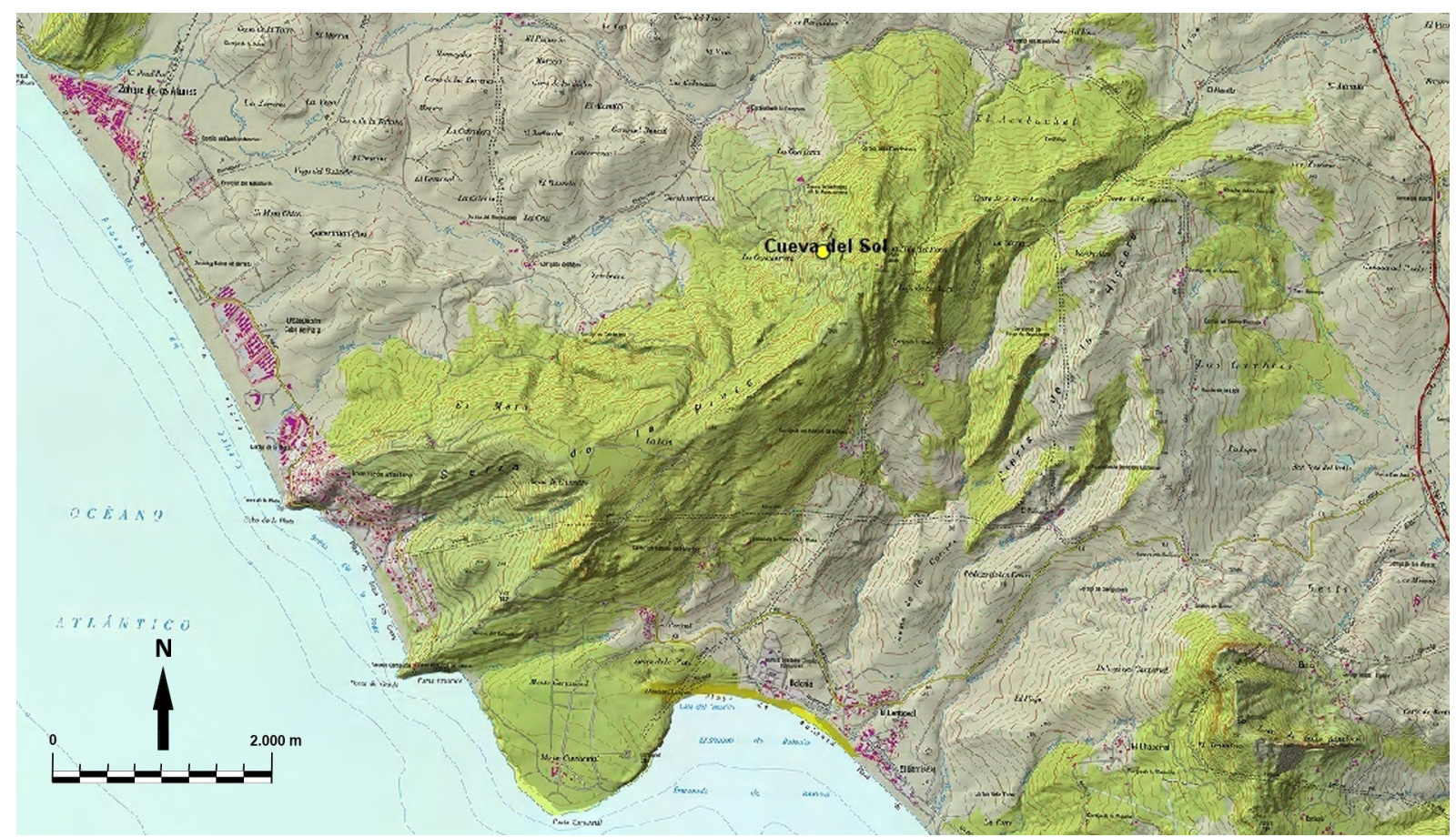

Figura 1. Ubicación topográfica de la Cueva del Sol. Mapa base: Mapa Topográfico Nacional (2012) 1:25.000 del @ Instituto Geográfico Nacional de España. 
Figura 2. Vista de la Sierra de la Plata.

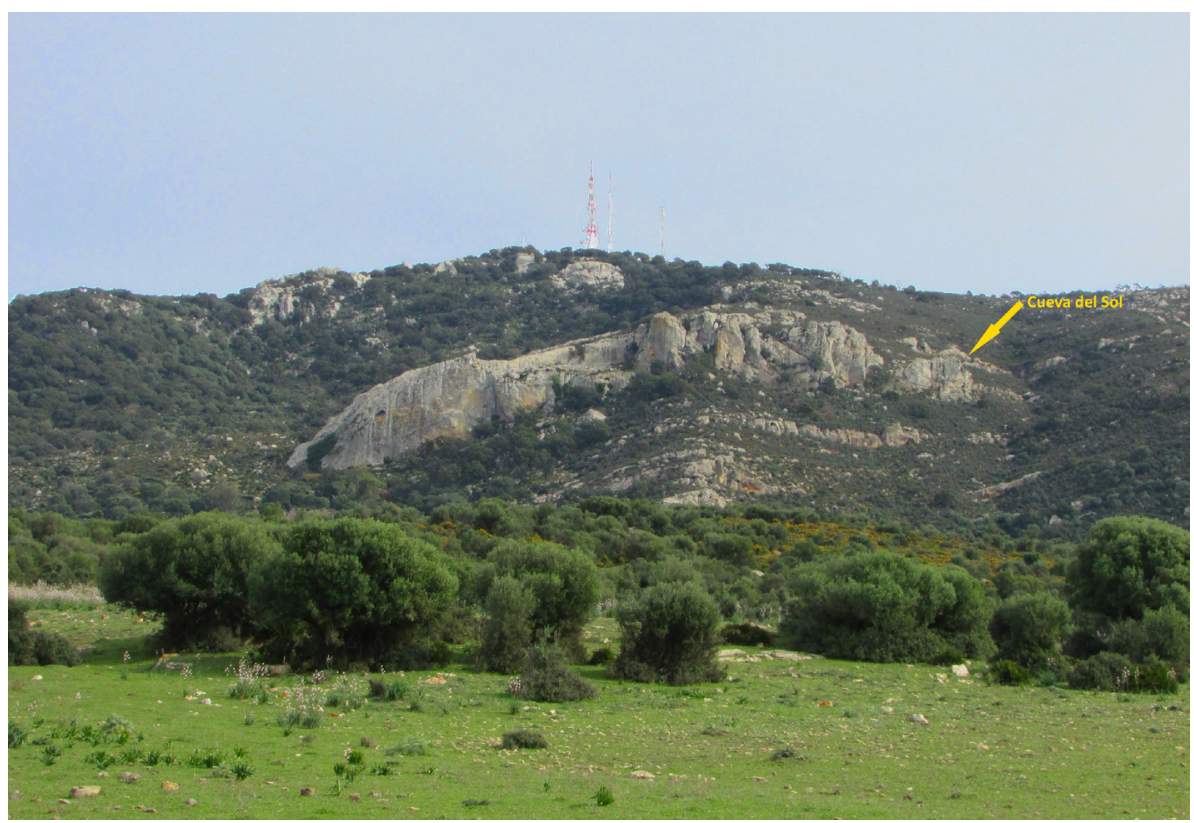

Desde Cueva del Sol (fig. 3) se domina una zona deprimida de unos $6 \mathrm{~km}$ de ancho y $5 \mathrm{~km}$ de largo que está comprendida entre la Sierra de la Plata y Sierra del Retín. Así mismo, se divisa una amplia perspectiva de la franja costera de la Banda Atlántica de Cádiz, que abarca desde la localidad de Zahara de los Atunes hasta Barbate. Aquí afloran las calizas, margas y arcillas de la unidad de Almarchal, que originan un relieve alomado con vegetación principalmente herbácea, y que constituye el paso natural entre la Laguna de la Janda y la franja litoral (Ruiz et al. 1990).

La Cueva del Sol es un abrigo de reducidas dimensiones $\left(4 \mathrm{~m}^{2}\right)$ y de planta circular (fig. 4). Está abierto al poniente y situado en las cercanías de la cabecera del arroyo del Candalar. La erosión eólica actuó sobre una diaclasa vertical de dirección norte, $9^{\circ}$ este, que afecta

Figura 3. Cueva del Sol.

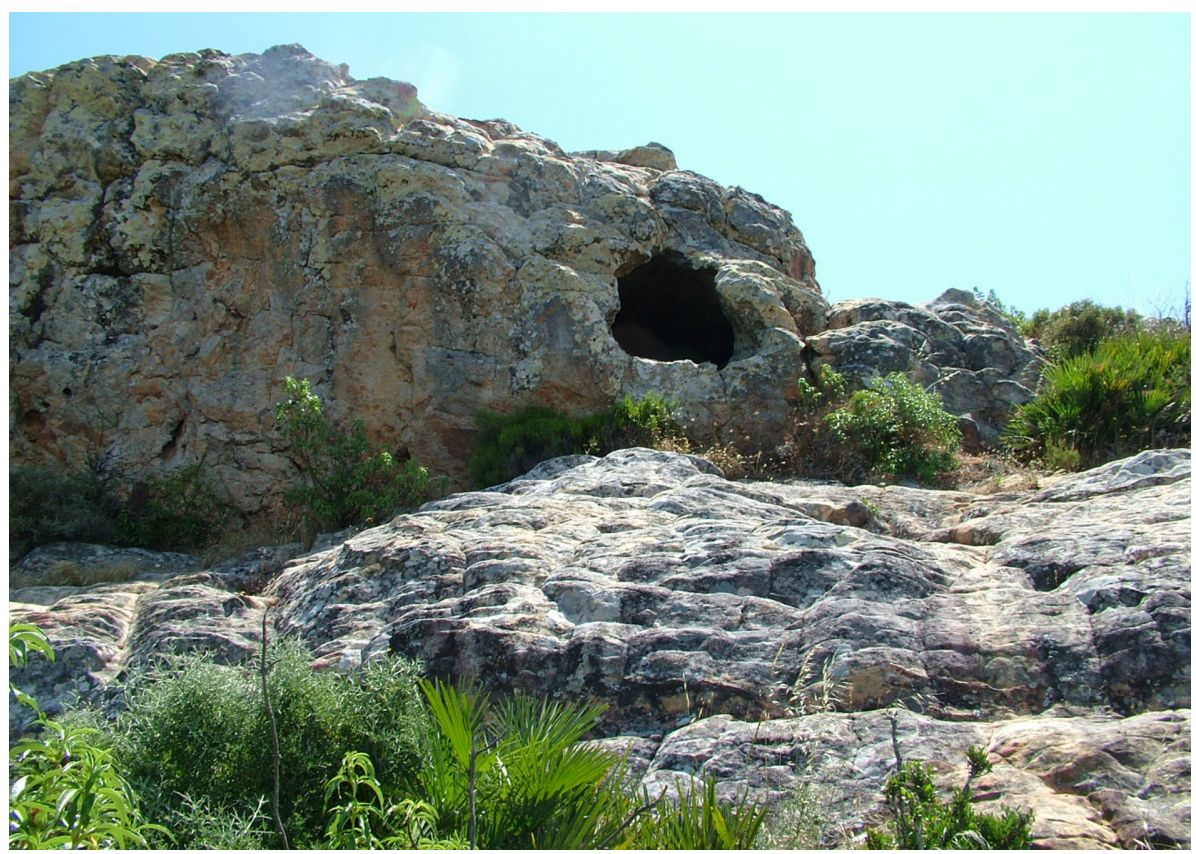

ISSN: 1133-4525 ISSN-e: 2255-3924 


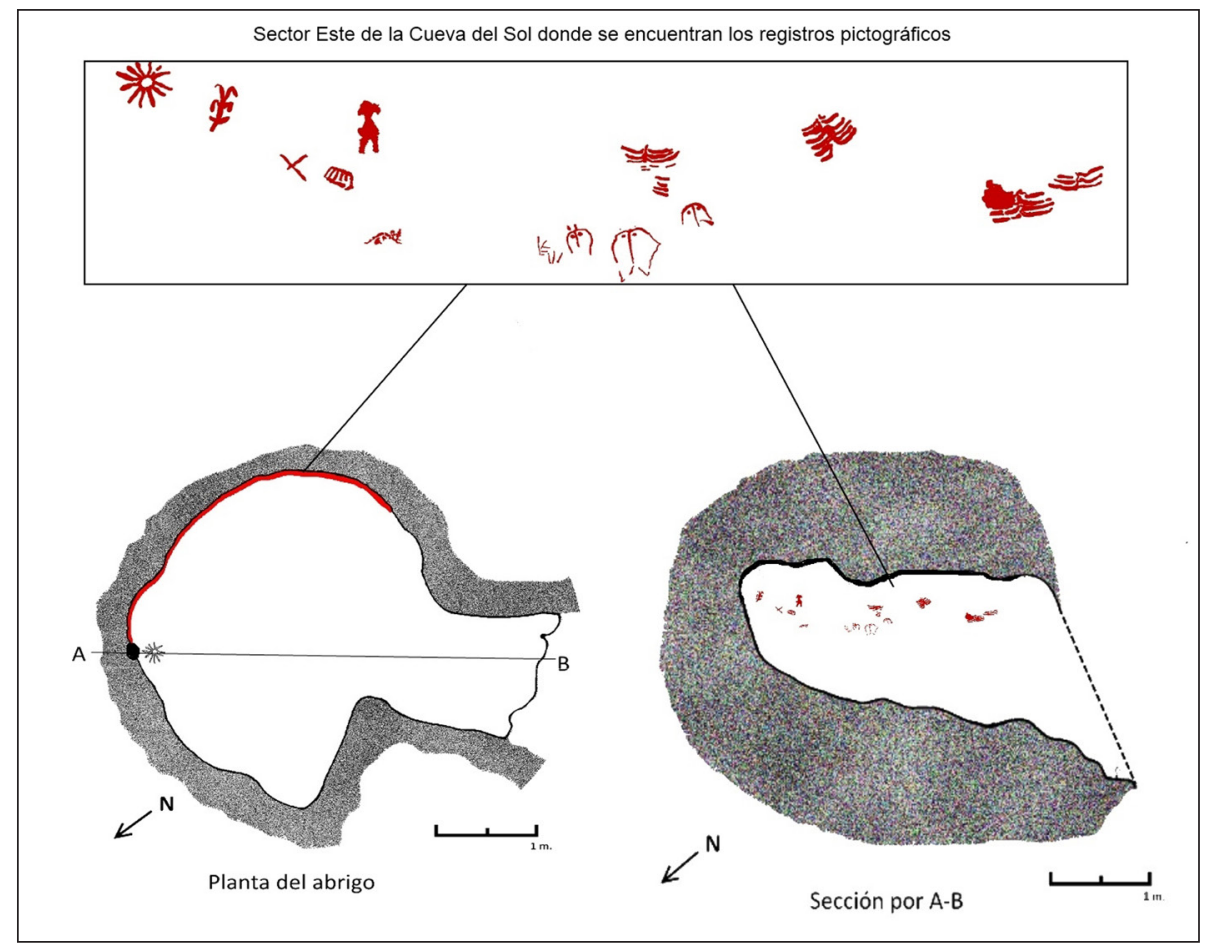

Figura 4. Planta y sección del abrigo.

a un estrato de unos $8 \mathrm{~m}$ de potencia de arenisca del Aljibe de dirección norte $20^{\circ}$ este y que buza $54^{\circ}$ al sur. Es una cavidad de difícil acceso ya que se encuentra en una zona muy escarpada de la sierra. Su orientación y tamaño la hacen prácticamente invisible al ojo humano desde la distancia.
El interior del abrigo en la actualidad está sujeto a una escasa erosión, al estar 'fosilizada' la mayor parte de su superficie, destacando solo los grandes alveolos desarrollados sobre el techo y la parte superior de los paneles (fig. 5).

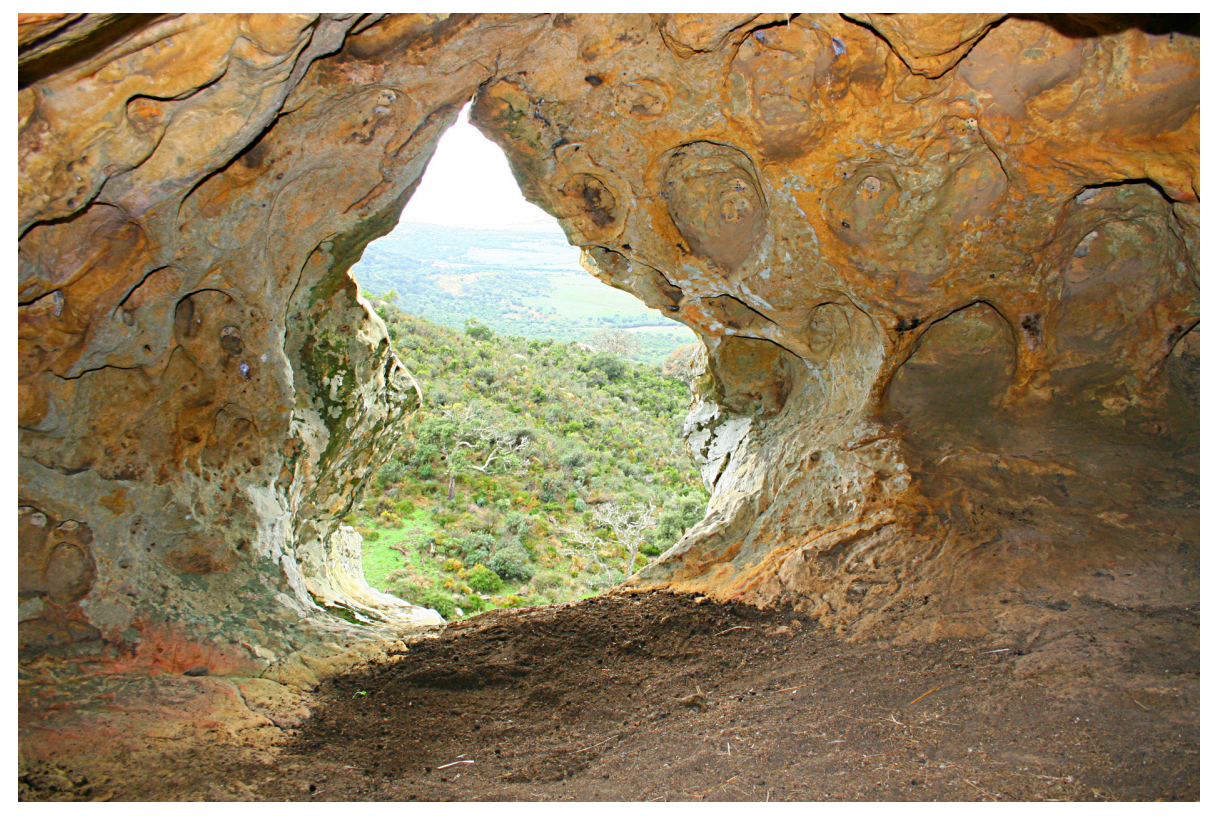

Figura 5. Superficie alveolar del interior del abrigo. 
Figura 6. Superficie de la pared del abrigo afectado por nidos de avispas terreras.

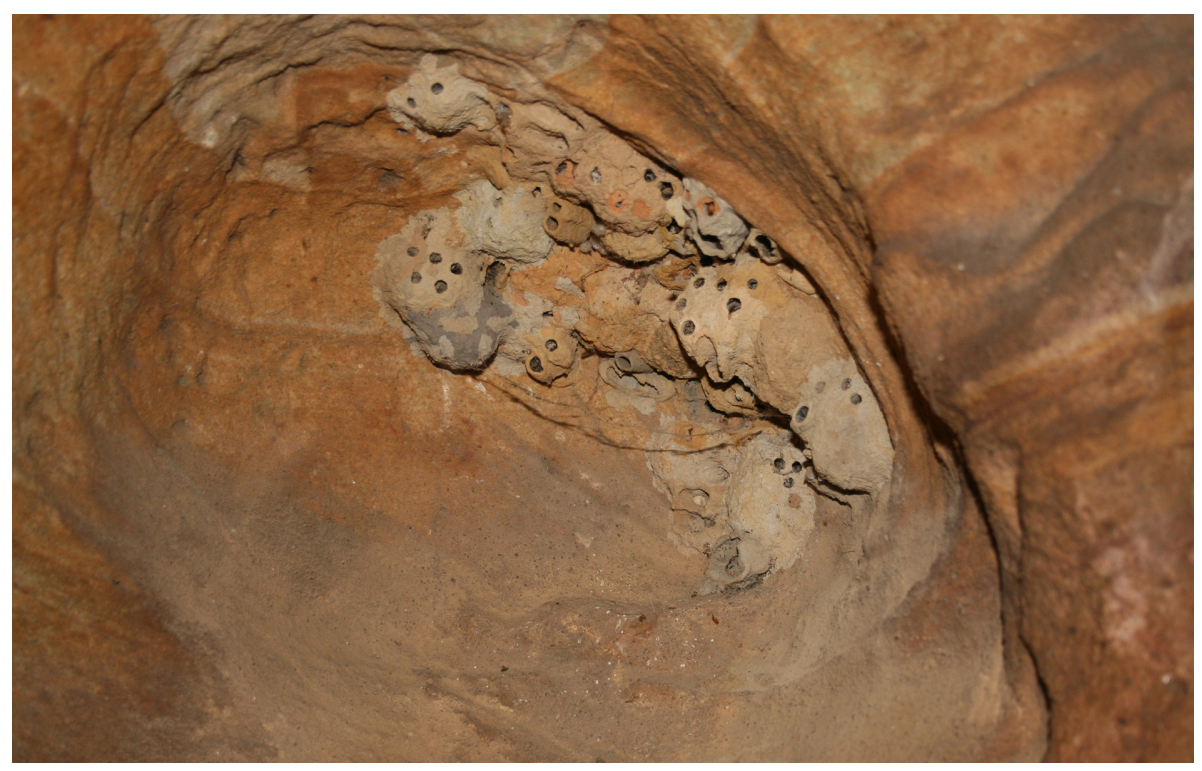

\section{METODOLOGÍA}

En el estudio de la Cueva del Sol se han alternado actividades de campo y de gabinete. Las primeras consistieron en campañas sobre el terreno para el registro fotográfico del abrigo y sus figuras, la toma de datos de sus mediciones y, durante el ocaso del solsticio de invierno (2014), la primera observación y registro de imágenes del comportamiento de la proyección de la luz sobre los paneles.

El trabajo en gabinete consistió fundamentalmente en el análisis de la información recogida en las actividades de campo, ya que los estudios y publicaciones sobre este abrigo son casi inexistentes. Se elaboró un banco de imágenes las cuales procesamos digitalmente con la herramienta informática Dstrech, un plugin para la aplicación ImageJ, específicamente diseñado para el tratamiento de imágenes de pinturas rupestres, a través del cual y siguiendo distintos métodos hemos podido extraer a la luz pinturas que apenas son visibles en el panel, así como yuxtaposiciones y repintes.

Para los cálculos astronómicos se utilizaron programas específicos elaborados al efecto por el IAC, los cuales fueron desarrollados en el lenguaje de programación Fortran.

Con respecto a los mapas georeferenciados de los abrigos, hemos utilizado la aplicación SIG gvSIG v. 1.12 y archivos ráster del Mapa Topográfico Nacional 1:25.000, que incluyen sombreado de relieve y obtenidos en la Web del Instituto Geográfico Nacional.

\section{ICONOGRAFÍA}

Antes de comenzar el análisis estilístico y su posible interpretación, es necesario aclarar que, al hallarnos en los inicios de esta investigación, preferimos remitirnos a las interpretaciones de Robert Bednarik, la cual compartimos:

Así, los parámetros que el investigador(a) escoge, inevitablemente reflejarán sus sesgos y limitaciones personales, culturales, históricas, etnocéntricas, académicas y cognitivas. En consecuencia, la información derivada es de utilidad solamente en los términos de análisis de la cultura y cognición propios del investigador, y en el estudio de la forma en que éste los aplica en el examen de los rastros gráficos que sobreviven de sistemas cognitivos ajenos y a los cuales él (ella) no tiene acceso cognitivo (Bednarik 2004).

La Cueva del Sol cuenta actualmente con 16 registros pictográficos que se encuentran en su totalidad en la mitad derecha de la cavidad. Los motivos se disponen en grupos, aparentemente asociados y de manera lineal.

Hay que señalar que, aunque las pinturas están poco afectadas por causas antrópicas, sí que lo están por fenómenos naturales (fig. 6).

Algunos motivos los encontramos intencionalmente semiocultos en oquedades (fig. 7) o aprovechando la geomorfología del abrigo con el objetivo de dar volumen a la figura.

Desde un punto de vista estilístico se podrían establecer dos categorías diferentes: el seminaturalista y el 


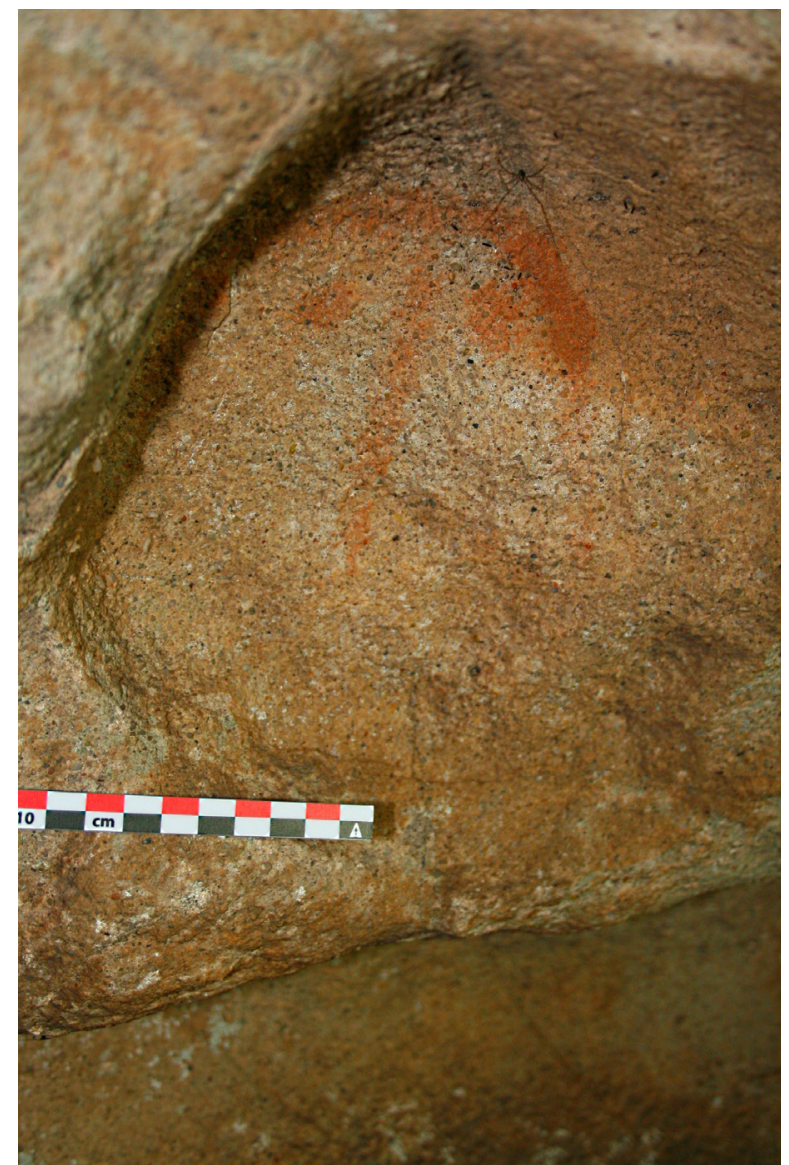

Figura 7. Registro 11, ídolo oculado realizado en una oquedad. esquemático típico (Sanchidrián 2001: 439), sin que ello implique necesariamente algún tipo de diacronía (Gómez-Barrera 2005: 24). El tamaño de las figuras en su gran mayoría es mediano, entre $10 \mathrm{~cm}$ y $24 \mathrm{~cm}$. La uniformidad en su gama cromática en rojo -color con predominio absoluto en el Arte Esquemático de la zona- y la de la técnica a trazo grueso -realizados con los dedos-, utilizada a la hora de realizar todas las pictografías, nos lleva a pensar en principio en una sola fase gráfica. A pesar de ello, detectamos un repinte en la figura soliforme, realizado, como es lógico, en un momento posterior a la ejecución inicial. Este afán de mantener las pinturas podría ser la prueba de un uso prolongado en el tiempo, tanto del abrigo como tal vez de su función.

Los 16 motivos identificados corresponden a 1 soliforme, 1 arboriforme, 1 antropomorfo, 1 escaleriforme, 1 cruciforme, 3 ídolos oculados, 5 de los denominados tatuajes faciales y 3 motivos indefinidos (fig. 8).

Describiremos las figuras antes mencionadas en tres grupos por posibles asociaciones y de izquierda a derecha, en el sentido de las agujas del reloj, como pensamos que fue la intención de los autores para que estos símbolos fueran vistos ("leídos") por los observadores.

$\mathrm{Al}$ entrar al abrigo lo primero que encontramos de frente es una figura soliforme realizada a modo de círculo radiado (fig. 9). Se trata de la figura de mayor tamaño de este tipo que hay en los 22 abrigos con soliformes que hemos registrado, hasta ahora, en nuestra base de datos. Mide $23 \mathrm{~cm}$ de diámetro. Los rayos que parten de dicho círculo son doce y mantienen una separación entre ellos que guarda la total armonía de la figura astral.

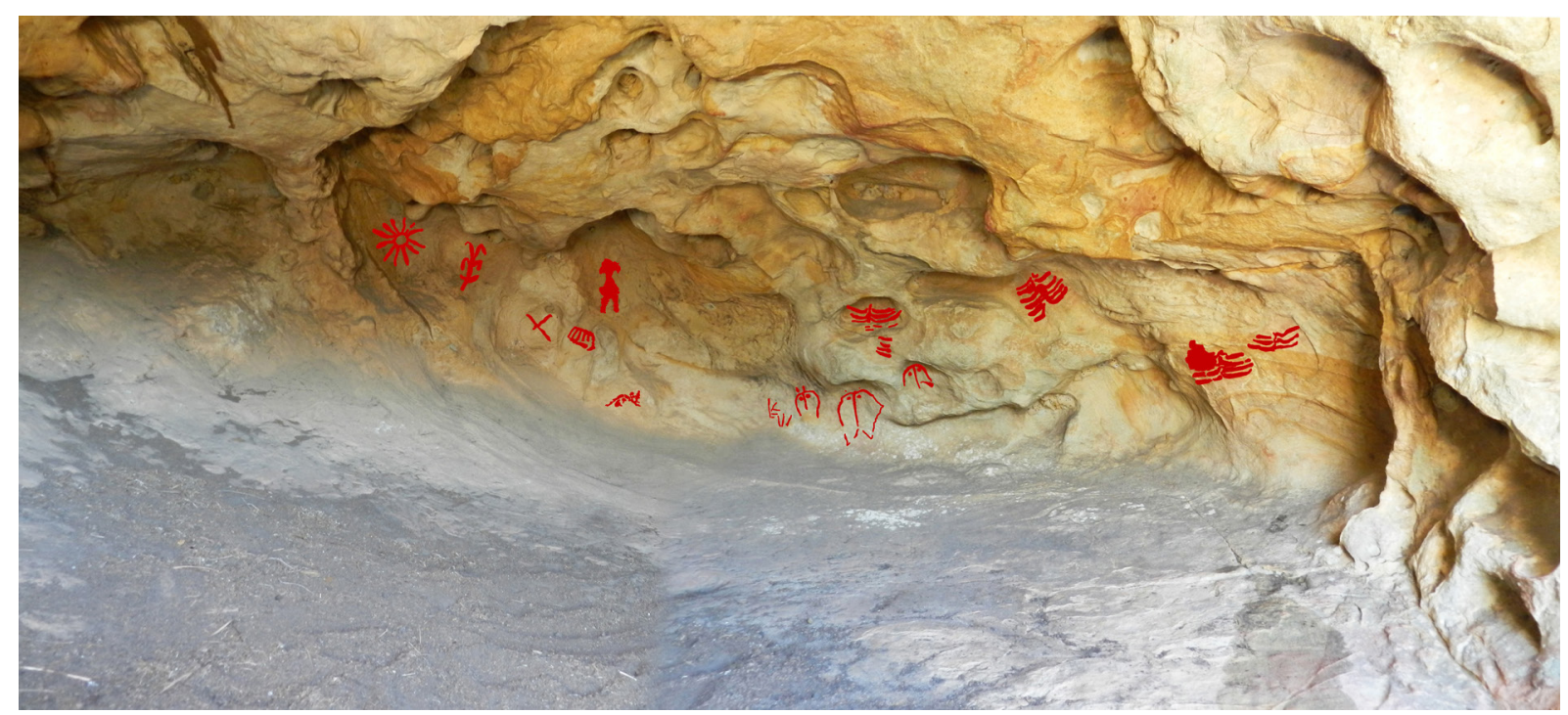

Figura 8. Panorámica del panel del abrigo con los 16 calcos de los motivos registrados (Foto Carlos Salas). 


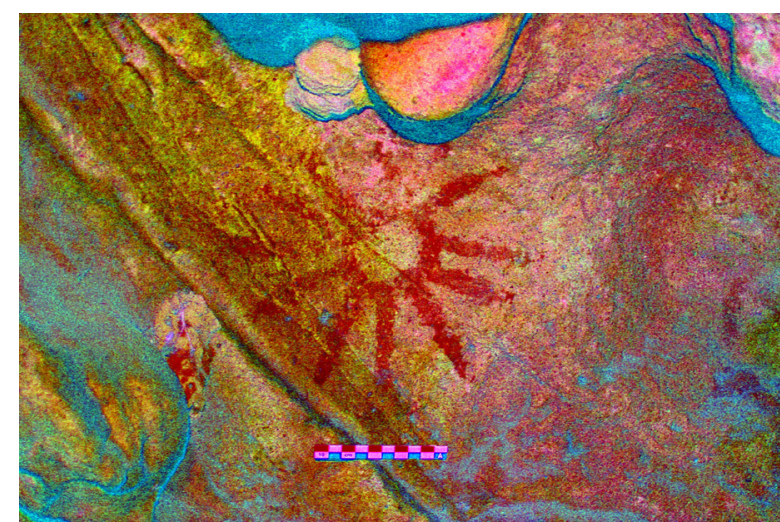

Figura 9. Foto tratada soliforme.

Las figuras asociadas a este motivo son un particular arboriforme, que muestra con gran detalle la morfología de lo que podría ser una planta de trigo (fig. 10), y un antropomorfo (fig. 11), ambos a la derecha del soliforme. De la asociación iconográfica soliforme-arboriforme $\mathrm{M}^{\mathrm{a}}$ del Rosario Lucas Pellicer nos dice que "Se trata de unas constantes en el modo de simbolizar conceptos que nacen con la economía agrícola y se mostraron universalmente eficaces en el significado intelectual y místico (...) el astro celeste y la vegetación" (Lucas 1990: 203).

En cuanto al antropomorfo representado es la única figura del abrigo que está realizada a tinta plana. A primera vista parece una figura acéfala, pero la ausencia total de restos de pigmentos donde debería estar la cabeza nos induce a pensar que, lo que podría interpretarse como hombros y brazos corresponden en realidad a una especie de tocado. Esta posibilidad se basaría en la propia esquematización de la figura y apoyándonos en estudios y clasificaciones estilístico-etnográficos (fig. 12) realizados tanto por Breuil y Burkitt (1929) y Pilar Acosta (1968), como por nuestro equipo de investigación (Carreras et al. 2011, Lazarich et al. 2012a y 2012b).

Este conjunto forma una 'triada' con una fuerte carga simbólica conceptual (fig. 13). Con respecto al escaleriforme (fig. 14) no podemos dejar de vincularlo a ella. De nuevo acudimos a las interpretaciones aportadas por R. Lucas Pellicer que manifiesta, por una parte, que esta figura, ya sea representada tanto horizontal como verticalmente, hace referencia a la ascensión; en el sentido de traspasar el plano profano para llegar o ascender al sagrado y, por otra, incide en el propio emplazamiento del abrigo ubicado en altura, sacralizando así el espacio natural (Lucas 1990: 201-203).

El segundo y tercer conjunto de figuras lo forman los 3 ídolos oculados y los 5 motivos denominados
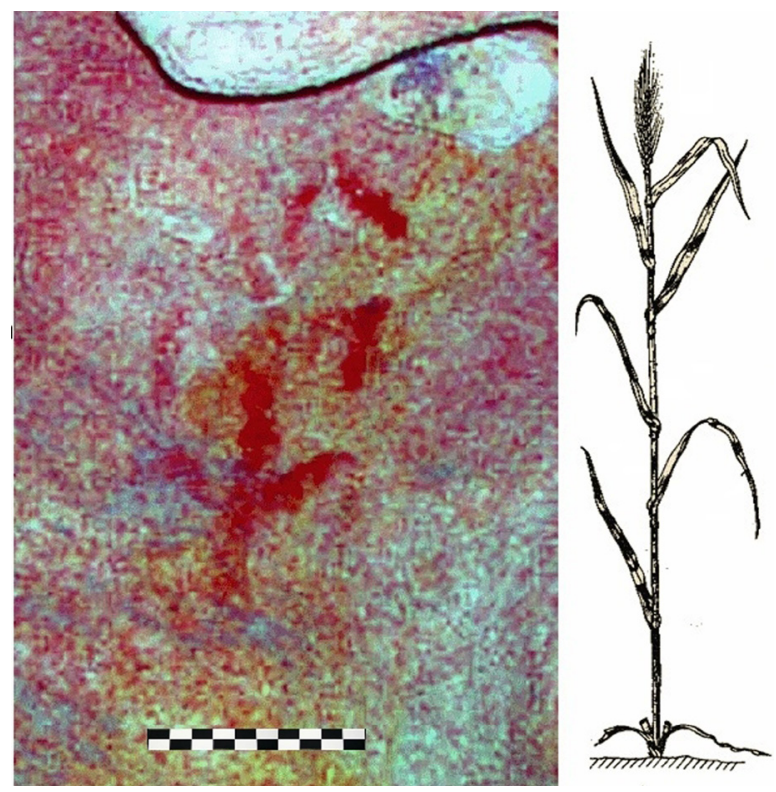

Figura 10. Foto tratada arboriforme. Comparativa con planta de trigo.

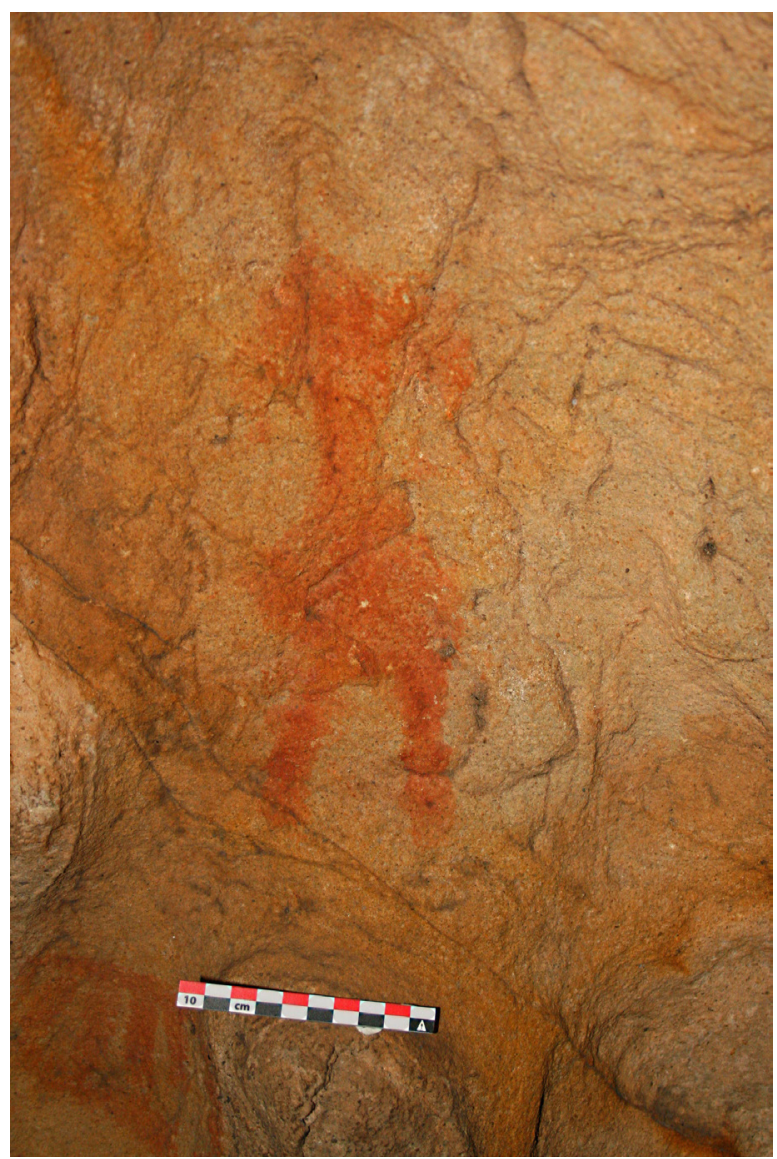

Figura 11. Foto tratada antropomorfo. 


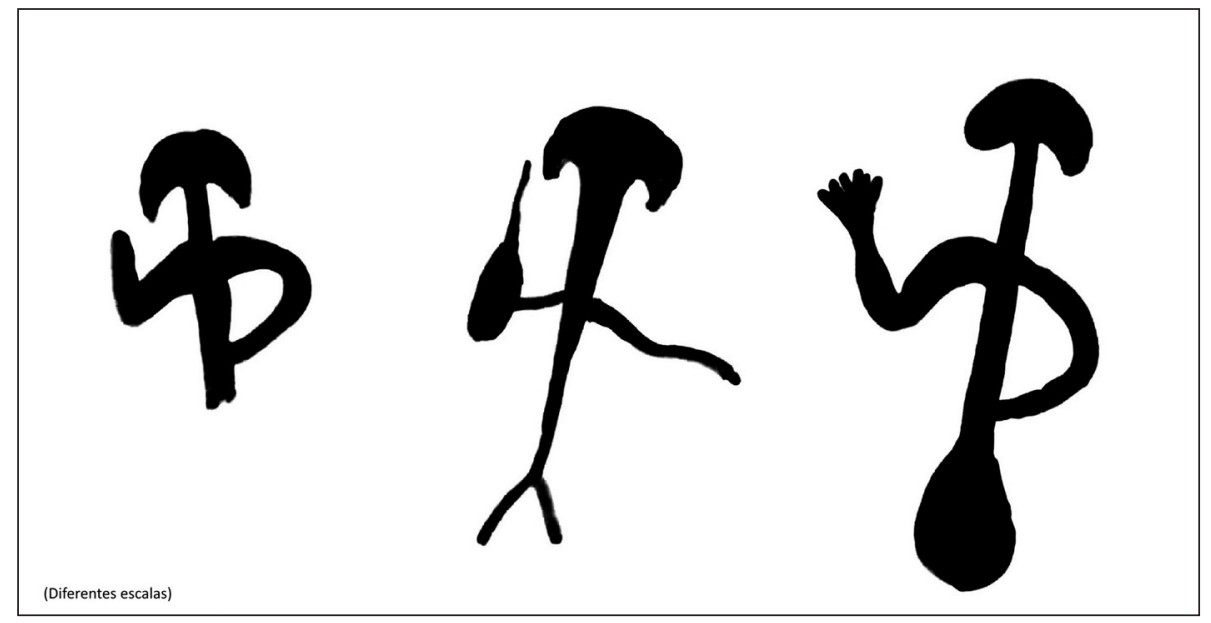

Figura 12. Tipología antropomorfos. Dibujado por A. Ramos, basado en H. Breuil y M.C. Burkitt (1929).

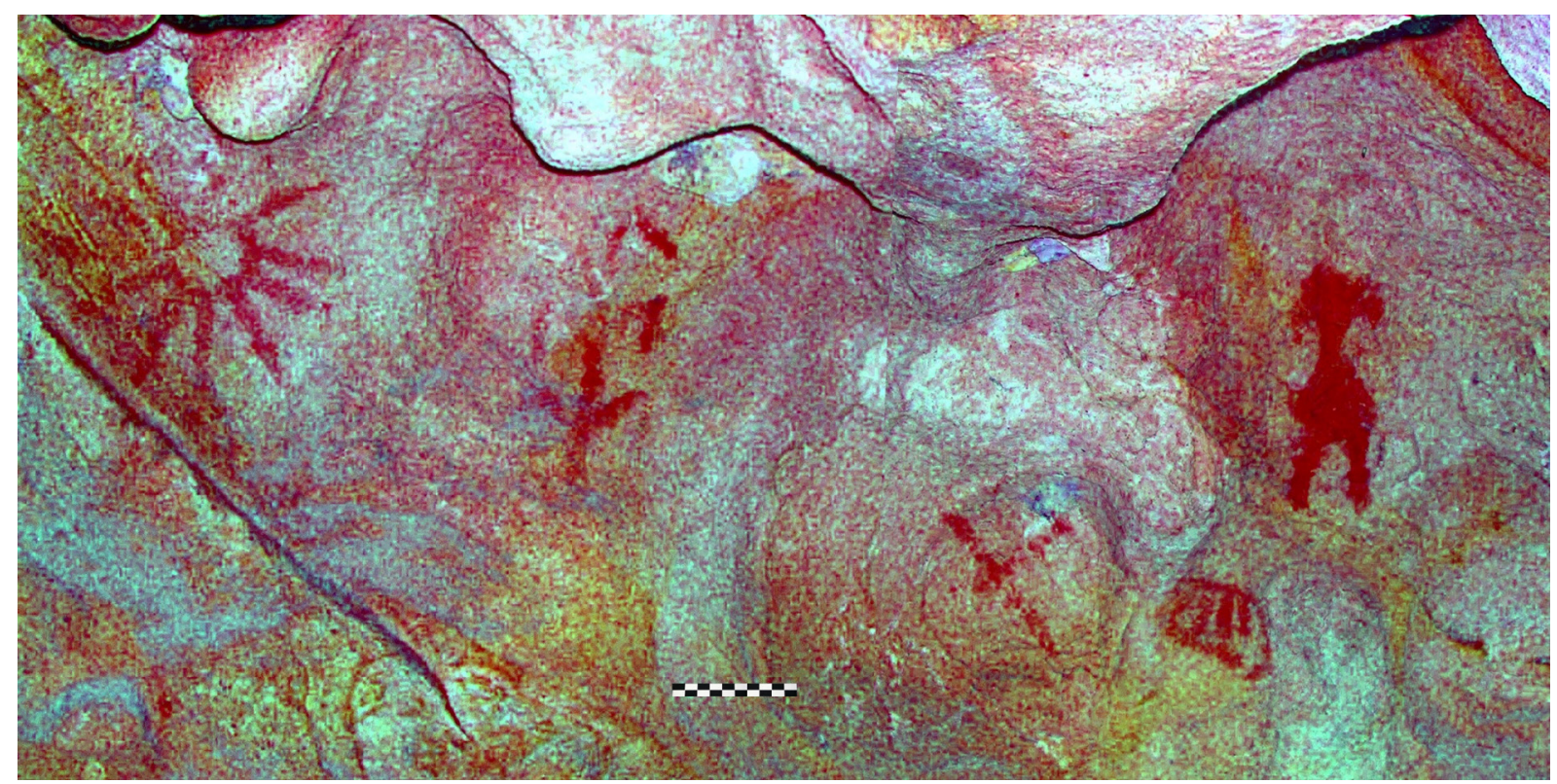

Figura 13. Foto tratada de figuras asociadas.

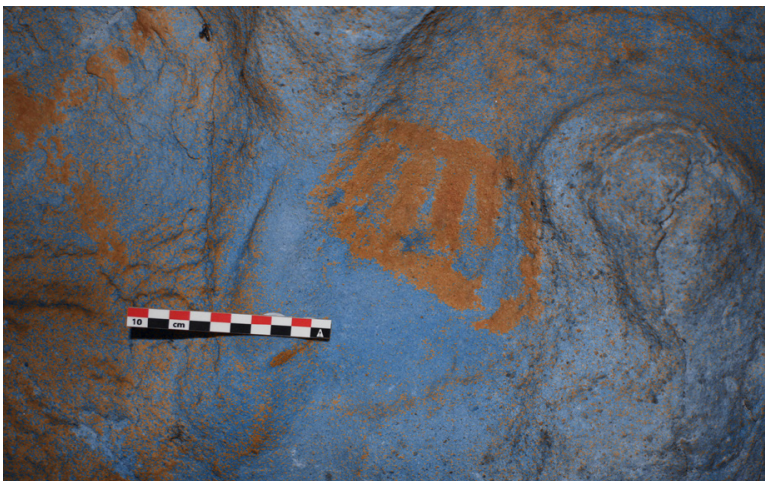

Figura 14. Foto tratada escaleriforme. tatuajes faciales (Acosta 1967: 67-70). La importancia de estos grupos radica, no solo en su posible interpretación sino que, además, nos sirven como 'fósil director' para la cronología de las pinturas (fig. 15).

El hecho de describirlos conjuntamente se debe a que tanto uno como otro motivo son elementos que, en ocasiones, forman parte de un mismo icono (fig. 16).

Durante el Calcolítico los llamados ídolos oculados tendrán una fuerte presencia en todo tipo de soporte y de contexto (Atienzar 2006). Esta irrupción iconográfica ocurrida en gran parte de la península ibérica pero, sobre todo, en la parte meridional de esta, nos habla de un cambio de las mentalidades, quizá del paso de una 

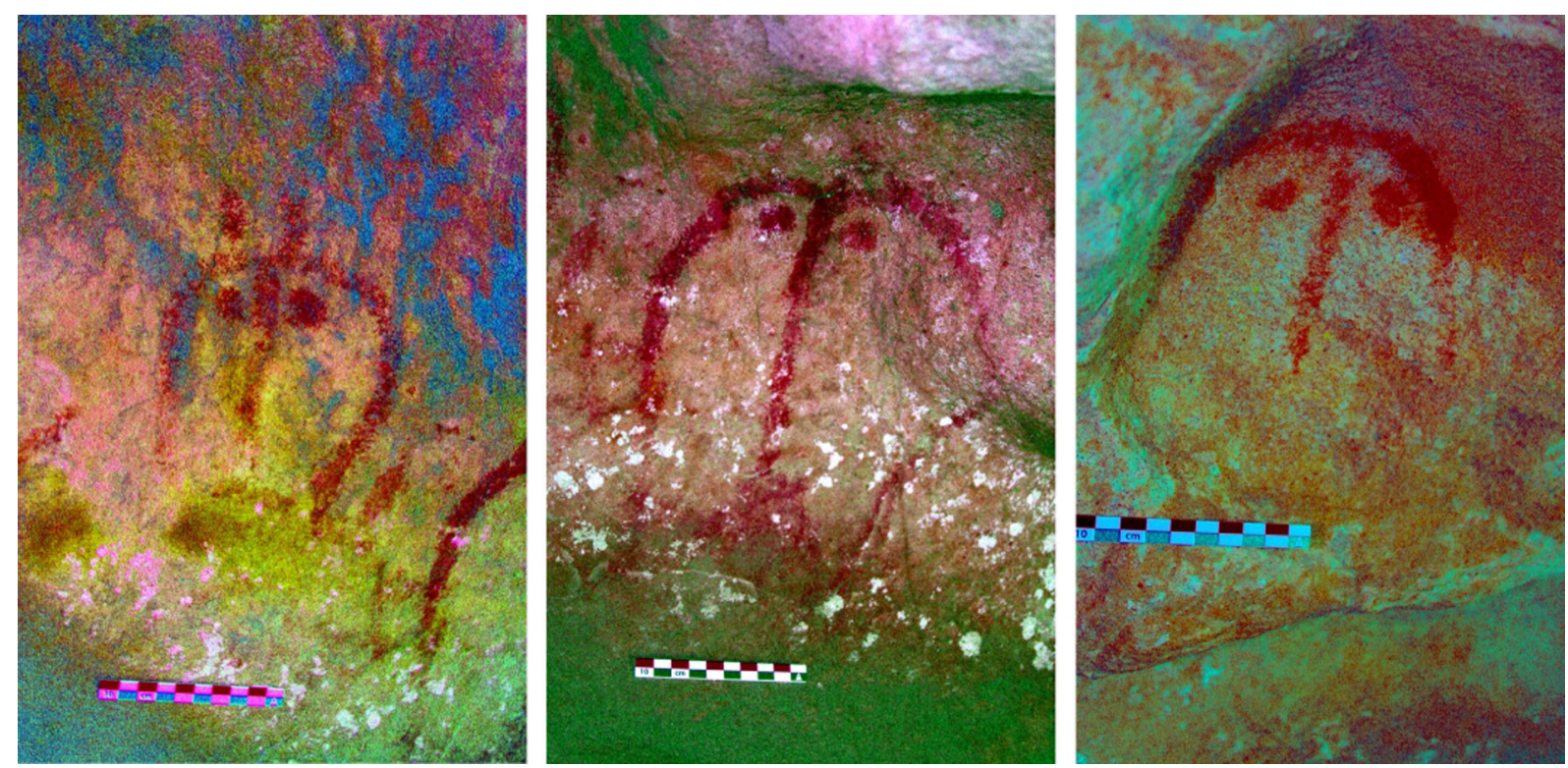

Figura 15. Fotos tratadas ídolos oculados.

práctica ritual solo mágica a una primera forma de religiosidad. Los cambios profundos que pudieron producirse a nivel social en este período, como por ejemplo el desarrollo tecnológico o los patrones de poblamiento entre otros, pudieron ser la causa de esta transformación en su mundo espiritual.

Los tres ídolos (fig. 15) propiamente dichos están ubicados en la parte inferior del gran panel que forma la mitad derecha del abrigo, mientras que los llamados tatuajes faciales los encontramos en la parte superior (fig. 16) y están distribuidos de una manera dispersa por la mitad derecha del único panel que existe en la cueva.

\section{RESULTADOS DE LA OBSERVACIÓN}

Al objeto de analizar el efecto de la iluminación de los paneles de Cueva del Sol durante el solsticio
Figura 16. Fotos tratadas tatuajes faciales.
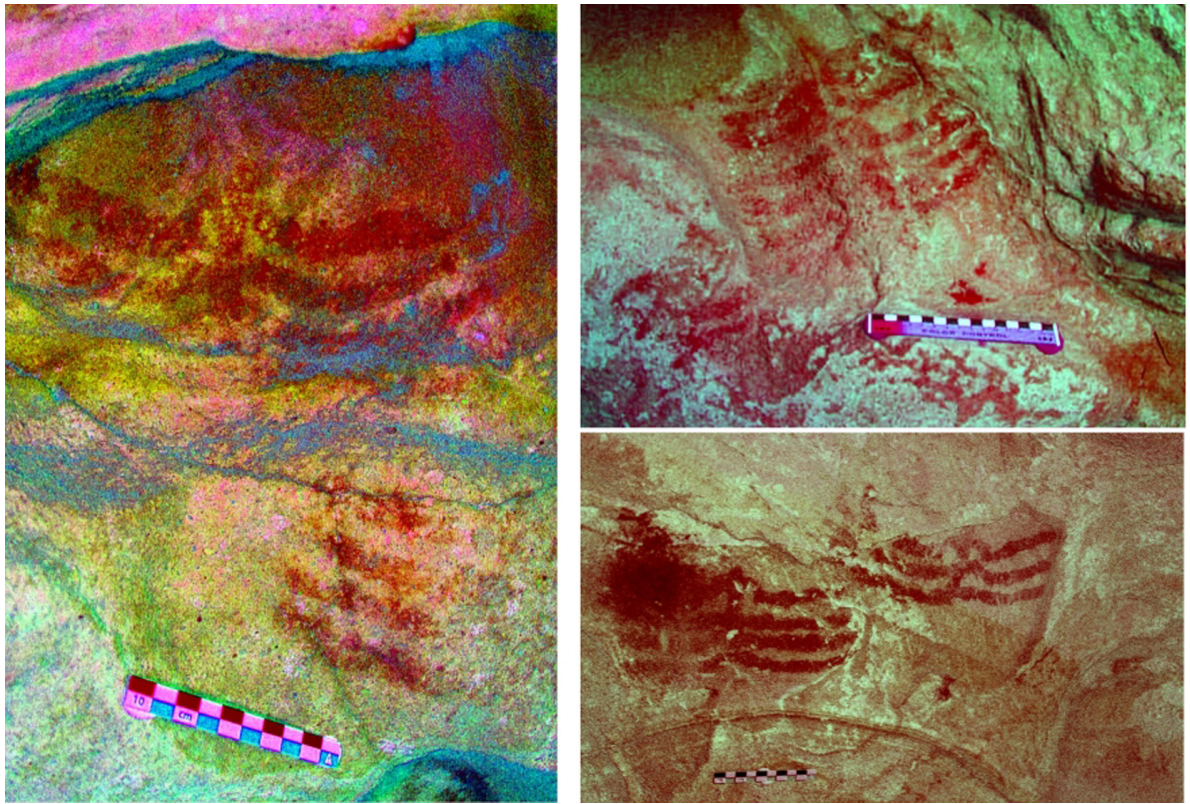

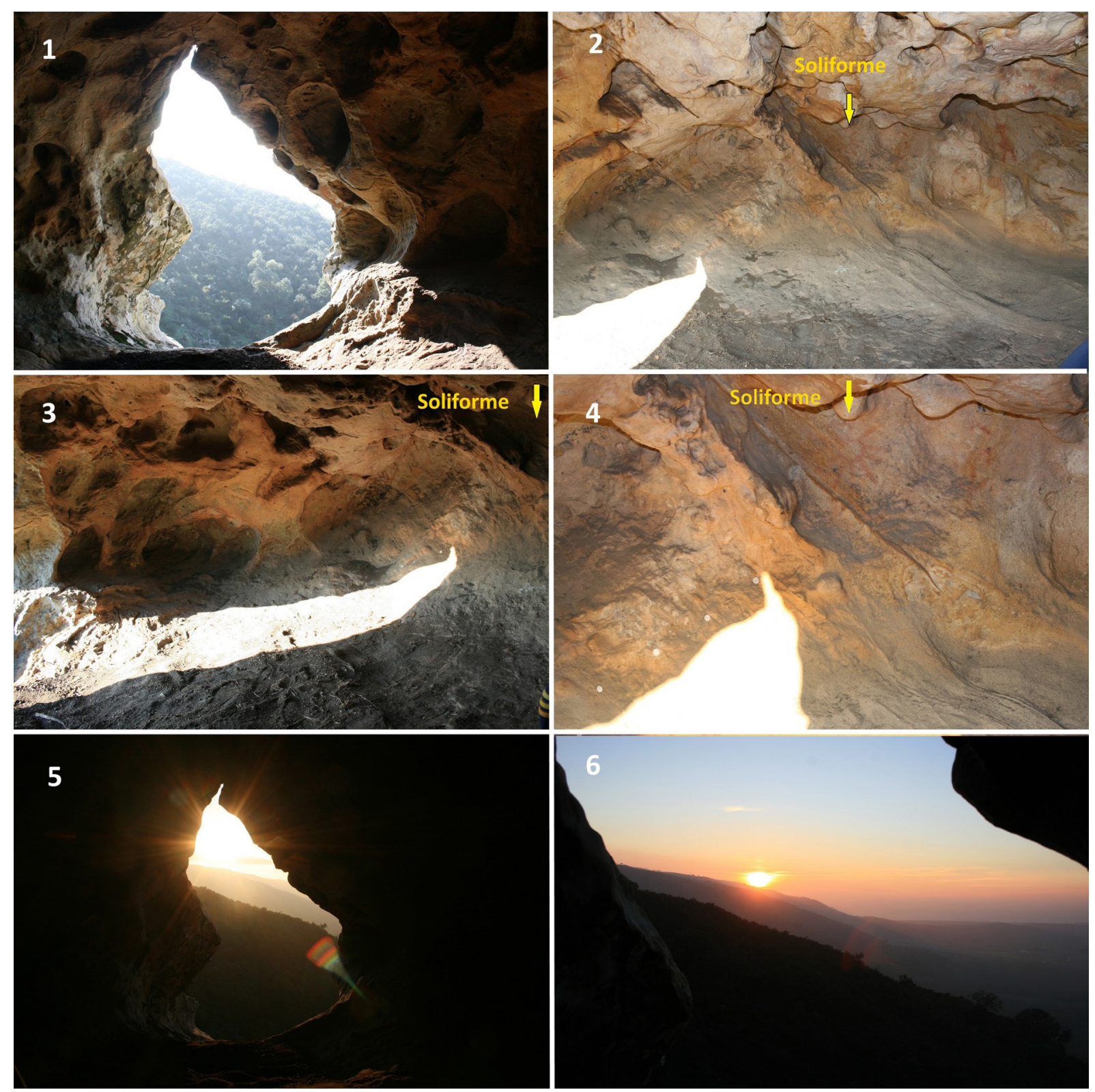

Figura 17. Secuencia de la observación astronómica I.

de invierno, decidimos analizar in situ dichas condiciones durante el solsticio de invierno de 2014, fenómeno que ocurre el 21 de diciembre. Debido a que los pronósticos meteorológicos para ese día 21 anunciaban la presencia de nubes y teniendo en cuenta que la diferencia en acimut al ocaso 5 días antes o después del día 21 es inferior a $2^{\circ} 30^{\prime}$ (diferencia despreciable a los efectos que nos interesan), realizamos la observación el día 18 de diciembre de 2014 a partir de las $15 \mathrm{~h}$.
A medida que el haz de luz iba recorriendo el suelo del abrigo, veíamos cómo el vértice superior de este (que evocaba la forma de un dedo) se aproximaba cada vez más a la figura soliforme (fig. 17). Con intervalos de 15 min fuimos poniendo una marca y midiendo la distancia que recorría dicho haz de luz en su aproximación al disco solar.

Aquella tarde el ocaso debía tener lugar en el horizonte a las 18:20 h.

Finalmente a las 18:10 h el sol alumbró uno de los rayos inferiores de la figura soliforme; a las 18:15 h 

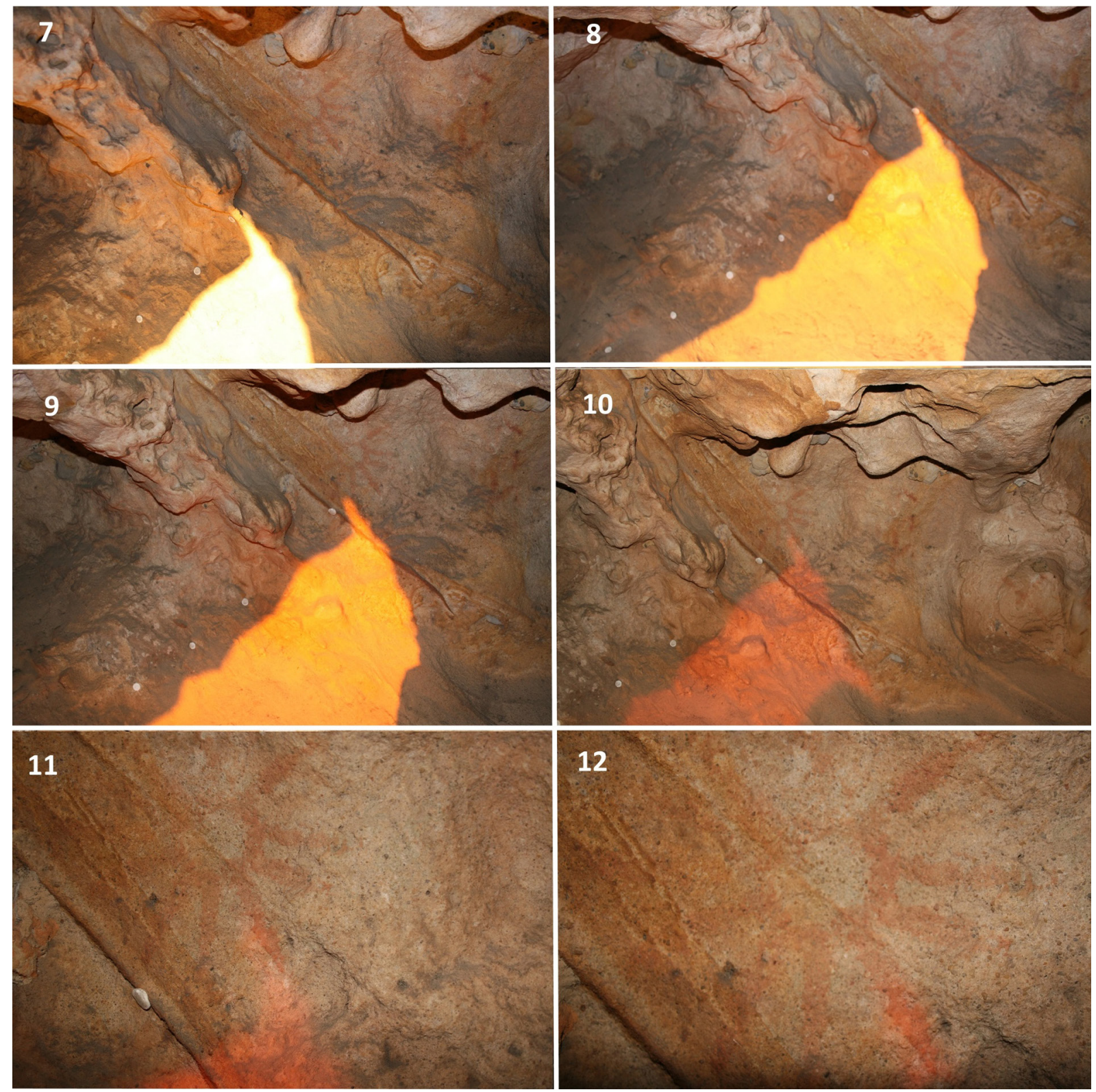

Figura 18. Secuencia de la observación astronómica II.

pasó al siguiente rayo, que además presenta el único repinte que hemos observado en el abrigo, para segundos después desaparecer definitivamente detrás de un pequeño cerro que se encuentra enfrente de la Cueva del Sol (fig. 18).

Con los datos que teníamos realizamos un cálculo aproximado de lo que sucedería en el próximo equinoccio y solsticio de verano, y ver así qué figuras estarían vinculadas a dichos fenómenos astronómicos.

\section{PREDICCIONES}

Nos propusimos como objetivo modelizar (fig. 19), para un instante cualquiera, la posición del vértice de luz proyectado sobre la pared del fondo del abrigo. La idea era comprobar si la puesta de Sol en fechas notables, como los equinoccios o los solsticios, coincidía con alguno de los motivos pintados, tal como ocurría en el solsticio de invierno con el soliforme marcado con la etiqueta 1 en la fig. 19. Para hacer dicha predicción es 
necesario en primer lugar calcular la posición del Sol en el firmamento para una fecha y hora dadas. Dicha posición viene determinada, como para cualquier objeto celeste, por dos coordenadas angulares: la altura (definida como el ángulo sobre el horizonte del objeto, es decir, su "altura angular" sobre el horizonte) y el acimut (ángulo medido sobre el horizonte, a partir del sur y en sentido sur-oeste-norte-este, de la proyección vertical sobre el horizonte, de la posición del objeto). En segundo lugar hace falta conocer la forma, medidas y orientación de la pared del fondo del abrigo, sobre la cual el Sol incide al atardecer. Este último factor fue el que limitó nuestra capacidad de predicción, debido fundamentalmente a la falta de recursos para tomar in situ las medidas adecuadas y con la precisión requerida. Por ello recurrimos a estimaciones de la posición y orientación exactas de las figuras pintadas sobre el panel, realizadas a partir de las medidas allí tomadas, y trabajamos bajo la hipótesis de un modelo simplificado de la geometría de la cueva. De todas formas, las distancias medidas sobre las fotografías tomadas en el abrigo permitieron ampliar y precisar, hasta cierto punto, la información necesaria.

El modelo simplificado de cueva con que hemos trabajado asume para la pared del fondo una forma semiesférica. Las posiciones que sobre esta pared idealizada se calcularon fueron las de la proyección del vértice superior de la boca de la cueva, es decir, las del vértice del haz de luz. Dicho punto superior de la entrada se encuentra a una altura de $15,5 \mathrm{~cm}$ sobre el nivel horizontal del soliforme y a una distancia horizontal de éste de $266 \mathrm{~cm}$. El ángulo que subtiende sobre el horizonte dicho vértice, visto desde el soliforme, es por tanto de $3^{\circ} 20^{\prime}$. A este respecto, cabe destacar que el hecho de que la sombra del vértice de la boca del abrigo incida en el soliforme en el momento del ocaso durante el solsticio de invierno se debe a que el horizonte real en ese instante está a esa elevación de $3^{\circ}$ $20^{\prime}$. La razón de que no esté a $0^{\circ}$, como correspondería a un horizonte en llano, se debe a la presencia de montañas delante de la cueva.

En el solsticio de invierno el acimut del Sol en su ocaso visto desde la cueva es casi exactamente $60^{\circ}$, mientras que en los equinoccios es $90^{\circ}$, por lo que en esta segunda fecha el Sol se pone $30^{\circ}$ más al norte que en la primera. Si suponemos, como se ha expuesto, que el fondo de la cueva es circular, implicaría que a la puesta de sol, en el equinoccio, el vértice de luz se encontraría a $139 \mathrm{~cm}$ a la derecha de su correspondiente posición para el solsticio de invierno, o lo que es lo mismo, del soliforme. Este punto está más a la derecha de la posición del ramiforme (fig. 19.2) y del antropomorfo (fig. 19.3); de hecho corresponde a las inmediaciones de la figura pintada en un hueco en la pared, a unos $72 \mathrm{~cm}$ a la derecha del antropomorfo (fig. 19.4).

No podemos precisar si el vértice de luz incidirá exactamente en esta figura porque sólo hemos podido determinar su posición de forma aproximada por las imágenes tomadas en la cueva, debido a que cuando se tomaron las medidas no preveíamos que el Sol incidiría tan lejos del soliforme, lo que motivó que no se efectuaran medidas precisas de la posición relativa de esta pintura. A partir de estas observaciones sabemos que la figura se encuentra a unos $158 \mathrm{~cm}$ a la derecha del soliforme. En cualquier caso, a pesar de esta imprecisión, sí podemos asegurar que el vértice de luz no se situará muy alejado de ella. La diferencia entre las distancias calculadas desde el soliforme hasta el vértice de luz proyectado a la figura citada es de unos $19 \mathrm{~cm}$, distancia que muy bien podría estar dentro de la imprecisión de las medidas estimadas para las posiciones de las pinturas, por no mencionar el tamaño de las propias figuras. Por tanto, concluimos que existe una probabilidad nada despreciable de que la luz del Sol incida en el instante del ocaso, durante varios días alrededor del equinoccio de primavera, sobre la fig. 19.4 pintada en el citado hueco. Dichos cálculos serán comprobados o refutados, si es el caso, en el próximo equinoccio de primavera cuando se lleve a cabo una segunda observación y estudio exhaustivo del abrigo.

En cuanto al solsticio de verano, aunque las predicciones son aún menos precisas, al ocaso del Sol el haz de luz se encontraría cerca de otra pintura más a la derecha aún de la citada fig. 19.4 y similar a ella (fig. 19.5). En cualquier caso, esta propuesta debe tomarse de momento como tentativa, hasta que no se realicen las pertinentes observaciones en el próximo estío.

Por otra parte, es importante comentar que no deben existir diferencias apreciables entre las posiciones actuales del vértice de luz proyectado durante los ocasos del Sol en los equinoccios y solsticios, y las correspondientes a la época en que fue pintada la cueva (aproximadamente unos 5.000 años antes del presente), ya que la posición del Sol en el horizonte en esos instantes notables sólo depende de la latitud del lugar y de la oblicuidad de la eclíptica, esto es, el ángulo que forma el plano del ecuador terrestre con el de la órbita de la Tierra alrededor del Sol. En un periodo de tiempo tan corto desde el punto de vista geológico, ni la latitud del lugar ni la orientación de la cueva deben haber variado de forma apreciable para los efectos que nos interesan. Algo más puede haber cambiado la 


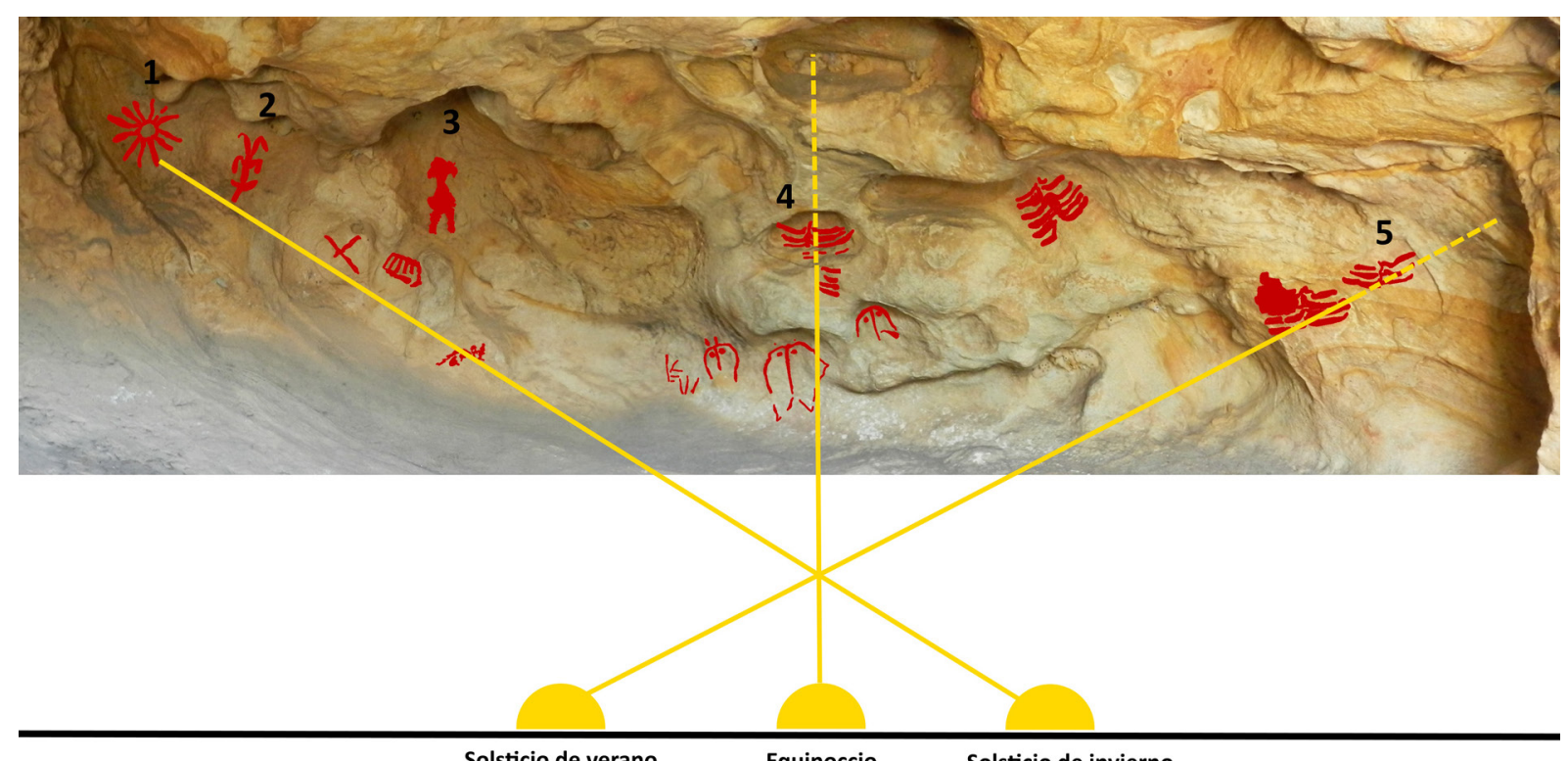

Solsticio de verano

Equinoccio

Solsticio de invierno

Figura 19. Esquema del marcador solar del solsticio de invierno, y predicciones para los equinoccios y solsticio de verano.

oblicuidad de la eclíptica (hasta 30' de arco), aunque tampoco lo suficiente como para tener un efecto significativo sobre el lugar de proyección del vértice de luz, dados los tamaños de las figuras pintadas sobre las que sería susceptible de incidir. Por tanto, el escenario descrito es esencialmente el mismo al vigente en el momento de ser pintada la cueva, al menos en lo que a la posición del ocaso del sol en los equinoccios y los solsticios se refiere.

\section{DISCUSIÓN Y CONCLUSIONES}

Con respecto a la cronología de las pinturas esquemáticas de la provincia de Cádiz, hasta hace muy poco tiempo se habían usado argumentos como las superposiciones o infraposiciones al arte levantino o en los paralelos con el arte mueble (Acosta 1984 y Carrasco et al. 2006). Esto ha creado muchas discrepancias en cuanto a su cronología.

A grandes rasgos podíamos decir que el Arte Esquemático de la península ibérica abarcaba una amplia franja cronológica, desde el Neolítico inicial a la Edad del Bronce. En 2012, un estudio multidisciplinar realizado en el Abrigo de los Oculados (Cuenca), pudo establecer las fechas anteriores y posteriores del momento en que se realizaron las pinturas, gracias a las pátinas de oxalato cálcico que encapsulan las pictografías datadas con $C^{14}$ (Ruiz 2012). Según los resultados las pictografías se realizaron entre 3500 a.C. y 1000 a.C. Fechas cal. 3630-3365 cal BC $(2 \sigma)$ y 910-540 cal BC $(2 \sigma)$. Precisamente, estas composiciones simbólicas, aunque tendrían su origen en el seno de las primeras comunidades agropastoriles (V milenio a.C.) evolucionarán y se desarrollarán a lo largo de la Edad del Cobre y los inicios del Bronce (entre el IV a.C. y los comienzos del II milenio a.C.), como queda reflejado en el registro arqueológico tanto mueble como inmueble (fig. 20).

Aunque los resultados son preliminares podemos abordar aspectos relativos a la función del abrigo apoyándonos en los resultados obtenidos de las observaciones astronómicas, el análisis del paisaje que rodea a la Cueva del Sol, el contexto arqueológico regional y el estudio iconográfico.

Para empezar partimos de la hipótesis de que la Cueva del Sol funcionó como un marcador solar del solsticio de invierno. Una vez verificado esto, nos preguntamos ¿cuál era su función? Los resultados de las predicciones obtenidas para los equinoccios y el solsticio de verano nos hacen pensar que, además de tener un uso vinculado al control estacional de las actividades agrarias, este abrigo se podría considerar como un lugar donde se perpetuaran, a través de algún tipo de ritual, los ciclos de la naturaleza y la resurrección misma 


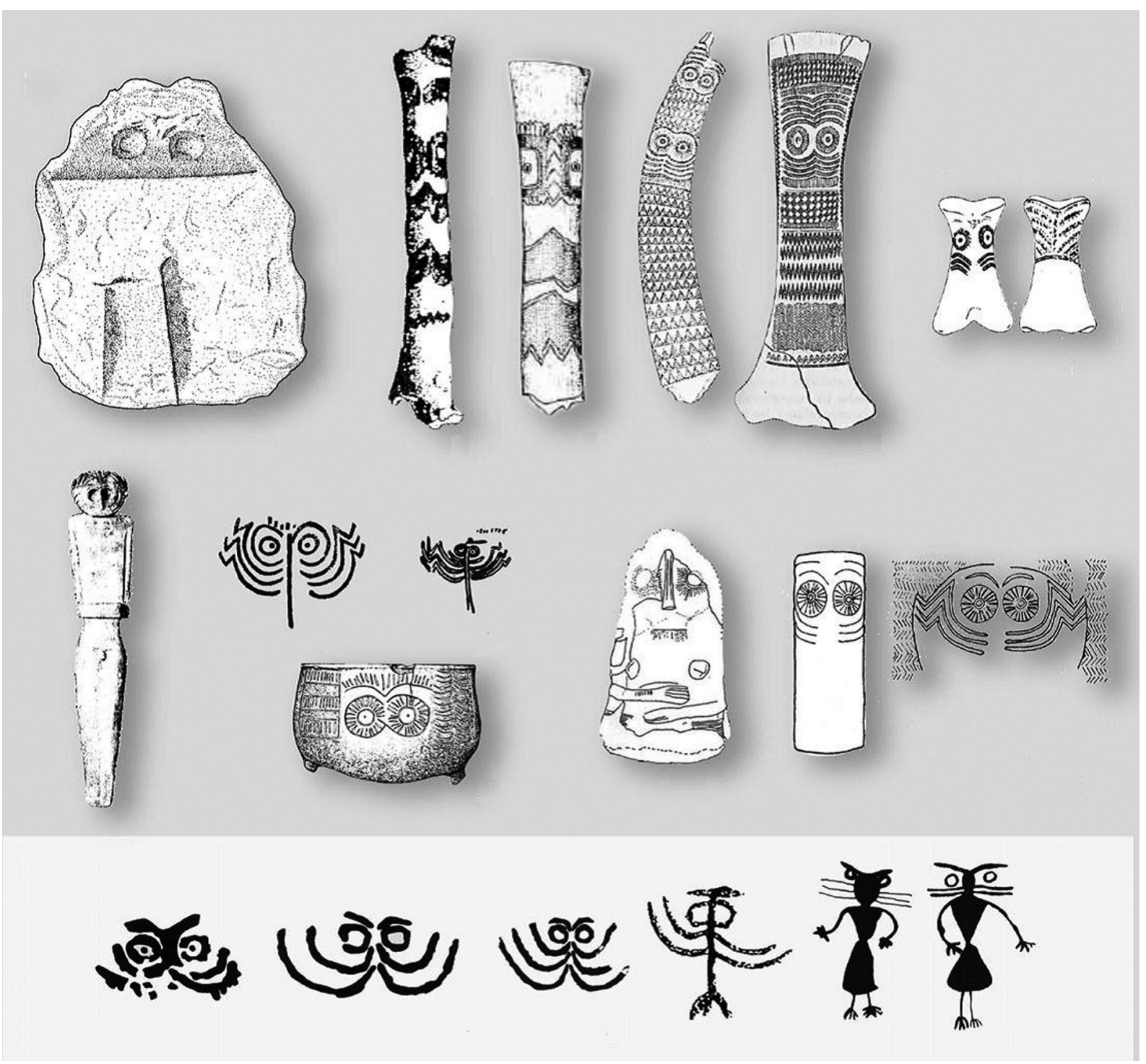

Figura 20. Tipología de los ídolos oculados ibéricos en el arte rupestre y arte mueble (según Ruiz 2012).

en su más amplio sentido. Pintando el Sol, atrapándolo en su momento de renacimiento (solsticio de invierno), y también al ramiforme como expresión de la tierra, de la regeneración de la vegetación, se asegurarían de que este ciclo no acabase jamás. En este sentido, los ídolos se encargarían, con su efecto apotropaico, de alejar aquello que pudiera impedir que se cumpliera el ciclo vital. Pero tal vez, no sólo esté vinculado a la resurrección del Sol y a la energía vital de la Tierra, sino que esté relacionado con la resurrección de los muertos. En este sentido, no podemos olvidar que los ídolos, en su versión de arte mueble, proceden en su gran mayoría de contextos funerarios. Nuevas interpretaciones sobre los llamados tatuajes faciales que ven en las líneas paralelas, típicas de este pictograma, posibles laceraciones o ablaciones faciales en el rostro como muestras de dolor (Escacena y Gómez 2016: 72-76), nos hacen volver la mirada, una vez más, al mundo de los muertos. Así, a tan solo $100 \mathrm{~m}$ de distancia de la Cueva del Sol existe una necrópolis megalítica, compuesta por numerosos dólmenes (Carreras et al. 2008) que no podemos dejar de relacionar con los hacedores de estas pinturas y el propio abrigo en particular.

Un ejemplo cercano del mismo caso en lo referente a la planificación del espacio social o territorio (santuario rupestre y necrópolis) lo constituye el conjunto de 
abrigos del Tajo de las Figuras y la necrópolis megalítica del Celemín ubicada a sus pies (Benalup-Casas Viejas, Cádiz) (Lazarich et al. 2012 a y b, 2013 a y b).

En resumen, consideramos que el abrigo Cueva del Sol pudiera estar vinculado al control estacional del solsticio de invierno durante la Edad del Cobre, como así también al mundo simbólico y a la cosmovisión de aquellos pobladores que habitaron las sierras del campo de Gibraltar y los entornos de la Laguna de La Janda.

\section{Agradecimientos}

Esta investigación se enmarca en el Proyecto de Actividad Arqueológica Puntual "Estudio y reproducción gráfica de abrigos con arte rupestre de la provincia de Cádiz", autorizado (DPPH-A-49/16(1087) por la Consejería de Cultura de la Junta de Andalucía a uno de los autores (MVI).

Queremos agradecer así mismo al doctor Cesar Esteban, del Instituto de Astrofísica de Canarias, por el asesoramiento científico que nos brindó en los primeros momentos de esta investigación. A Fernando Pardo de Donlebún por su ayuda práctica en todo lo referente a las aplicaciones informáticas que se usaron durante este estudio. Y por último a Joseph Prescott por su ayuda imprescindible durante las actividades de campo.

\section{BIBLIOGRAFÍA}

Acosta, P. (1967): Representaciones de ídolos en la pintura rupestre esquemática española. Trabajos de Prehistoria 24: 1-75.

Acosta, P. (1968): La pintura rupestre esquemática en España. Memorias del Seminario de Prehistoria y Arqueología de la Universidad de Salamanca, n. 1. Universidad de Salamanca, Salamanca.

Acosta, P. (1984): "El arte rupestre esquemático ibérico: problemas de cronología preliminares", en Scripta Praehistorica. Francisco Jordá Oblata Salmanticae: 31-61. Universidad de Salamanca, Salamanca.

Algarra, M. (2008): "El complejo del Campo de Gibraltar", en J.A. Vera y J.M. Molina (coords.), Proyecto Andalucía. Tomo XXVI, Geología II: 286-294. Sevilla - A Coruña, Publicaciones Comunitarias, Grupo Hércules.

Bednarik, R. G. (2004): “Arte rupestre, tafonomía y epistemología” (Traducido por Diego Martínez y Pedro Argüello). http://rupestreweb.tripod.com/ bednarik2.html. (Consulta 12 de enero de 2015)
Bergmann, L. (1994): "Nuevas cuevas con pinturas rupestres en el término municipal de Tarifa", en III Jornadas de Historia del Campo de Gibraltar. Almoraima 13: 51-61

Breuil, H. y Burkitt, M. C. (1929): Rock Paintings of Southern Andalusia. Oxford. Clarendon Press.

Carrasco, J.; Navarrete, M. S. y Panchón, J. A. (2006): "Las manifestaciones rupestres esquemáticas y los soportes muebles de Andalucía", en J. Martínez y M. S. Hernández (eds.), Actas del Congreso de Arte rupestre esquemático en la Península Ibérica: Comarca de los Vélez, 5-7 de Mayo 2004. Ayto. de Vélez-Blanco,Almería: 85-108.

Carreras, A.; Gomar, A.; Trujillo, A.; Lazarich, M. y Bergmann, L. (2008) "Las pinturas rupestres de la Sierra del Retín, Barbate (Cádiz)" Almoraima 36: 9-19.

Carreras, A.; Gomar, A.; Versaci, M.; Ruiz Trujillo, A.; Torres, F. y Díaz, F. (2011): “Análisis comparativo de las representaciones humanas y faunísticas en el arte rupestre postpaleolítico en las sierras del Parque Natural de los Alcornocales y del Estrecho de Gibraltar (Cádiz)". Almoraima 42: 263-285.

Escacena, J. L. y Gómez-Peña, A. (2016) "Símbolos de duelo. Sobre el mensaje de las máscaras gesticulantes fenicias" Madrider Mitteilungen, 57: 62-87.

Esteban, C. y Aura, E. (2001): "The winter sun in a Palaeolithic cave: La Cova del Parpalló". en C. Ruggles, F. Prendergast y T. Ray (eds.), Astronomy, Cosmology and Landscape: 8-14. Sussex, Ocarina Books.

Fernández, M. (2003): Las pinturas rupestres esquemáticas del Valle de Alcudia y Sierra Madrona. Ciudad Real, Mancomunidad de Municipios del Valle de Alcudia y Sierra Madrona.

Gómez-Barrera, J. A. (2005): "La pintura rupestre esquemática como acción social de los grupos agroganaderos en la meseta castellano-leonesa". Cuadernos de Arte Rupestre 2: 11-58.

Lazarich, M.; Carreras, A. Ma; Ramos, A.; Versaci, M.; Briceño, E.; Ruiz-Trujillo, A.; Gomar, A.; Sánchez, L.; Díaz, F. y Cruz, M.J., (2012 a): $\square$ Arte Rupestre y costumbres funerarias prehistóricas. Investigación, difusión y puesta en valor del Patrimonio Histórico del Parque Natural de los Alcornocales (Cádiz), en I Congreso Internacional El Patrimonio Cultural y Natural como motor de desarrollo: investigación e innovación: 1448-1465. CEI, Jaén.

Lazarich, M.; Gomar, A. Ma; Ruiz-Trujillo, A.; Torres, F.; Ramos, A. y Cruz, M ${ }^{\mathrm{a}}$ J. (2012 b): "Las manifestaciones postpaleolíticas del entorno de la Laguna 
de la Janda. Nuevas perspectivas de estudio", en $\mathrm{Va}$ ria X. Ponencias del seminario de Arte Prehistórico de 2011: 181-207. Valencia, Diputación de Valencia.

Lazarich, M.; Ramos, A.; Briceño, E.; Cruz, M.J.; Sañudo, J.; Pérez de Diego, Ma A., (2013 a): "La necrópolis megalítica del conjunto rupestre Tajo de las Figuras", en II Congreso de Prehistoria de Andalucía: 357-363. Antequera (2011). Antequera, Conserjería de Cultura. Junta de Andalucía.

Lazarich M.; Briceño E.; Cruz, Mª J.; Sañudo J. y Ramos-Gil, A. (2013 b): “Las necrópolis megalíticas del entorno de la Laguna de La Janda (Cádiz)", en VI Encuentro de Arqueología del Suroeste Peninsular: 208-228. Gráficas Reja, Mérida.

Lucas, M. R. (1990): "El santuario rupestre del Solapo del Águila (Villaseca, Segovia) y el barranco sagrado del Duratón", en I Coloquio Internacional sobre Religiones Prehistóricas de la Península Ibérica. Zephyrvs XLIII: 199-208.

Ruiz, J. F.; Hernanz, A.; Armitage, R. A.; Rowe, M. W.; Viñas, R.; Gavira-Vallejo, J. M. y Rubio, A. (2012): "Calcium oxalate AMS ${ }^{14} \mathrm{C}$ dating and chronology of post-Palaeolithic rock paintings in the Iberian Peninsula. Two dates from Abrigo de los Oculados (Henarejos, Cuenca, Spain)". Journal of Archaeological Science 39: 2655-2667.

Ruiz, M. D.; Rodríguez, P. y Carrasco, F. (1990): “Mineralogía y génesis de las arcillas de la unidad de Almarchal (series flysch del Campo de Gibraltar, S de España)". Estudios Geológicos 46: 165-173.

Sanchidrián, J. L. (2001): Manual de arte prehistórico. Barcelona, Ariel. 